\title{
The novel use of phase change materials in an open type refrigerated display cabinet: A theoretical investigation
}

\author{
F.A. Alzuwaid, Y.T. Ge*, S.A. Tassou, J. Sun \\ RCUK National Centre for Sustainable Energy use in Food chains (CSEF), Brunel University London, Uxbridge, Middlesex UB8 3PH, UK
}

\section{A R T I C L E I N F O}

Article history:

Received 19 April 2016

Received in revised form 18 June 2016

Accepted 18 July 2016

Available online $\mathrm{xxx}$

\section{Keywords:}

Integrated display cabinet model

CFD

Phase change material

Model validation and application

Energy savings

\section{A B S T R A C T}

In this paper, 2D CFD models have been developed for a prototype refrigerated open type multi-deck display cabinet with and without integrated phase change material (PCM). The models can predict the effect of adding a PCM container on cabinet efficiencies, air temperature distributions, product temperatures and air flow patterns inside the cabinet at a range of operating conditions including space air temperatures and evaporator air velocities. To validate the cabinet models, the prototype cabinet was mounted in an air conditioned chamber and extensive experiments were conducted at constant space air temperature and relative humidity. The cabinet models have therefore been validated through comparison with experiment results for air temperatures at different locations of the airflow path and of food products. Simulation results show that significant energy can be saved through the installation of a PCM container. Further benefits include greater stabilization of product temperatures during defrost periods for the modified display cabinet. Consequently, the validated models can be used to explore and analyse the cabinet performance and control strategies at various operating and design conditions.

CC 2016 Published by Elsevier Ltd.

\section{Nomenclature}

$C_{p}, c \quad$ specific heat capacity $(\mathrm{J} /(\mathrm{kg} \mathrm{K})$

$H, h$

$k$

$\mathrm{K}$

$L$

$\dot{\boldsymbol{m}}$

$P$

$Q$

$q$

$Q_{\text {source }}$

$S_{k}$

$S_{\varepsilon}$

$S$

$T$

$t$

$U, u$

$V, v$

V

$x$

$y$

\section{Greek symbols}

$\mu \quad$ viscosity (Pa s)

$\alpha \quad$ thermal diffusivity $\left(\mathrm{m}^{2} / \mathrm{s}\right)$

$\Gamma \quad$ diffusion coefficient

\section{* Corresponding author.}

Email address: Yunting.Ge@brunel.ac.uk (Y.T. Ge) turbulent kinetic energy $\left(\mathrm{m}^{2} / \mathrm{s}^{3}\right)$

liquid fraction

difference

\section{Subscripts}

evap evaporator

$l \quad$ liquid

ref reference

$S \quad$ solid

$W, w \quad$ with $P C M$

Wo, wo without PCM

a air

airon evaporator air on

airoff evaporator air off

$k \quad$ turbulent kinetic energy $\left(\mathrm{m}^{2} / \mathrm{s}^{2}\right)$

\section{Introduction}

Open multideck refrigerated display cabinets (MDC) are extensively used in retail stores in the United Kingdom and around the world to store and display dairy and chilled food products within permitable temperatures. Such cabinets are common and preferable in terms of saving floor space whilst simultaneously maintaining a sizeable retailing surface. The total length of these display cabinets can reach up to $100 \mathrm{~m}$ in a typical superstore, altogether contributing considerably to its overall energy consumption. In the UK, around $35-45 \%$ of the total energy consumption of a typical supermarket is used for refrigeration purposes, and around $70 \%$ of this refrigeration energy is required for MDCs [1]. Correspondingly, such consumption can indirectly contribute towards a vast amount of $\mathrm{CO}_{2}$ emissions. 
Meanwhile, if supermarket refrigeration systems were charged with HFC refrigerants such as R404A, a significant amount of $\mathrm{CO}_{2}$ will be directly produced due to unavoidable refrigerant leakage. All these concerns are driving the demand for the development of sustainable refrigeration technologies, with particular focus on the MDCs in supermarkets.

Conventionally, there are a number of technology options to reduce the MDC cooling load and thus improve unit performance. These include the optimal air curtain designs, better air flow distributions inside the cabinet, appropriate refrigerant selections and high efficient cabinet evaporators etc. [2-4]. It is known that of the total cooling load in an MDC, over $70 \%$ is produced by infiltration from the external space to the cabinet inside through the air curtain. One way to reduce the infiltration load is to modify the air flow rate from the air curtain jet. Based on a validated 3D CFD model of an MDC, it was found that the optimum mass flow rate of the air curtain should account for about one third of the total air mass flow rate from the cabinet evaporator outlet [5]. In such circumstances, the rest of the air flow would penetrate from the back flow channel into the cabinet through a perforated back panel. The interaction between air flows surrounding the cabinet will significantly affect cabinet performance and food storage; however, this could be evaluated by using validated CFD modelling technology and thus optimising the designs [6,7]. A validated cabinet model could be an efficient tool to examine cabinet performance, conduct optimal designs and most importantly, imitate actual cabinet operation. Accordingly, a compete cabinet model was developed by integrating two parts of cabinet sub-models in which a CFD model was utilised to predict the air flow dynamics surrounding the cabinet from the evaporator outlet to the inlet while a detailed model was developed for the evaporator [8]. Such a complete model is believed more practical since unnecessary assumptions of boundary conditions at the evaporator inlet and outlet were disregarded.

On the other hand, the integrations of PCMs into refrigeration systems, and particularly refrigerated display cabinets, have attracted greater interest recently considering its potential energy savings and temperature uniformity control of food production storage $[9,10]$. A recent experimental investigation on an MDC with and without PCM integration revealed some benefits for the unit with PCM, including uniformity of food product temperatures, less compressor on/off frequencies and reduced power consumption [11]. The technology with PCM integration could be further improved by selecting and producing more appropriate PCMs in different refrigerated cabinets [12]. The applied PCMs were originally paraffin and water but when an additional agent (AgI) was added and mixed, the cabinet performance could be further improved in term of energy savings. In addition, further benefits were found experimentally when heat pipe technology was combined with PCM utilization in the cabinet [13], these being moderate food product temperature rises during the defrost period.

Although energy storage with PCMs can play an important role in the performance of refrigerated cabinets, much of the previous research in this area dealt with experiments with limited test conditions. To facilitate the application of PCMs in MDCs, detailed theoretical or modelling analyses need to be conducted so as to predict and evaluate the performance of cabinets with PCMs at larger-scale operating conditions. This will lead to optimal selections of PCMs, PCM heat exchangers and their installation. It is therefore the purpose of this paper to develop a detailed CFD model for the MDC with PCMs and validate the model with corresponding test results. The validated model then compares the performance with the same cabinet but without PCMs in terms of energy saving and food product temperature variations etc. Further development in this area will also be recommended. Regarding to the novelty of this paper, so far, to the au- thors' understanding there is not a validated simulation study on the integration of PCM with the refrigerated open-type display cabinets. In addition, this paper has firstly developed a complete dynamic CFD model for an open-type display cabinet with the integrations of PCM heat exchanger, thermostat control, defrost and cabinet evaporator and compressor. This dynamic model can therefore simulate and understand completely and accurately the actual cabinet operation and be used as an efficient tool to optimise the cabinet performance and PCM integration.

\section{Experimental setup}

An integral low-fronted multi-deck open display case was selected as an experimental prototype in this study (Fig. 1). The cabinet dimensions included $1.25 \mathrm{~m} \times 0.85 \mathrm{~m} \times 1.98 \mathrm{~m}(\mathrm{~W} \times \mathrm{D} \times \mathrm{H}), 3.15 \mathrm{~m}^{2}$ refrigerated area and $1.5 \mathrm{~m}$ display opening height and was equipped with single air curtain situated from the top (base +5 shelves). The cabinet was loaded according to British standard (BS EN ISO, 23953-2: 2005) with test products used to simulate the thermal mass of food under real conditions. Those products were cooled by the low temperature air flow from the cabinet evaporator outlet which passed vertically in the back flow channel of the cabinet before reaching to the air curtain. Part of the air flow in the back channel emitted horizontally into the case inside through the perforated back panel and mixed into the air curtain and hence returned back to the evaporator inlet to be cooled again. The cabinet utilised off-cycle for defrost and required product temperature variation from $0{ }^{\circ} \mathrm{C}$ to $+4{ }^{\circ} \mathrm{C}$

The experiment design and setup had also been built according to the rules specified in BS EN ISO 23953-2: 2005 standard to measure air temperature and velocity and product temperature variation through the display cabinet. A series of preliminary experiments were prepared and carried out in order to find out the optimum operating setting and desirable air-off temperatures for the cabinet. Consequently, as indicated in Fig. 2, a temperature sensor located between

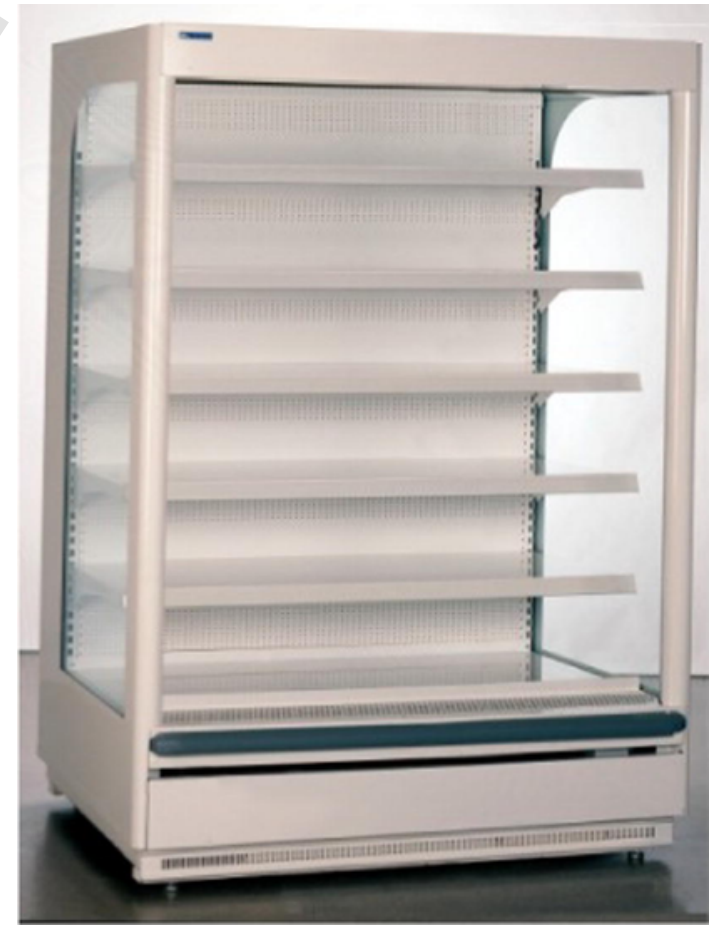

Fig. 1. Tested display cabinet. 
Thermostat Temperature

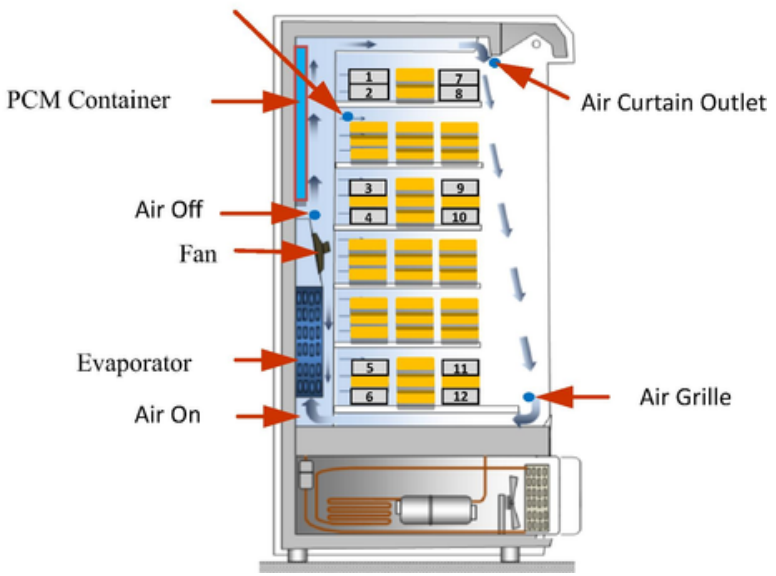

Fig. 2. Left side view of the cabinet with products.

the 1st and 2nd shelves was applied to monitor and control the cabinet temperature through the refrigeration system on/off.

The optimum settings for that monitoring point were obtained:

- Temperature setting point $=-0.7^{\circ} \mathrm{C}$.

- Dead band $=1.1 \mathrm{~K}$, the compressor stopped upon reaching the lower band and restarted at the temperature value above the upper band.

- Intervals between defrost $=4 \mathrm{~h}$

- Defrost stop temperature $=11^{\circ} \mathrm{C}$.

All these experiments have been performed under climate class 3 and at stable conditions where the chamber was controlled at a constant dry-bulb temperature $\left(25^{\circ} \mathrm{C}\right)$, a constant relative humidity $(60 \%)$ and air cross flow velocity at $0.1-0.2 \mathrm{~m} / \mathrm{s}$ over the experiment period of $24 \mathrm{~h}$.

During experiment periods, several important parameters were measured and recorded including: cabinet power consumption, temperatures of products, air curtain, cabinet inside air and evaporator air on and off. The products were loaded upon the shelves at the top, middle and bottom levels, as numbered and shown in Fig. 2, based on the standard of BS EN ISO 23953-2: 2005. There were twelve product simulators positioned on the left and right at both front and rear ends on each shelf. A calibrated thermocouple (type T) was inserted into each product simulator (M-pack) to measure the average temperature which was sampled every $10 \mathrm{~s}$ by a data acquisition system, and saved onto a data file every $60 \mathrm{~s}$ to be processed shortly afterwards.

All the sensors in the system were calibrated before the experiments to ensure acceptable accuracy with temperature uncertainty less than $\pm 0.5 \mathrm{~K}$, humidity $\pm 3.0 \%$ and air velocity $\pm 0.015 \mathrm{~m} / \mathrm{s}$ and power meter $\pm 0.05 \%[11]$.

\subsection{PCMs and integration}

Water gel based PCM with a nucleate agent was proposed in this work. Water gel PCM was composed of deionised water, silver iodide (AgI) to reduce the water sub-cooling, guar and sodium tetra borate [12]. Since freezing onset of the PCM depends on the location installed inside the cabinet, in this work, the PCM heat exchanger was applied and installed at just after evaporator coils. Therefore, based on the air-off temperature range, the PCM freeze onset was around $-2.0^{\circ} \mathrm{C}$. As illustrated in Fig. 2, a PCM container was used in this experiment separately. During the defrost period when the compressor is switched off, the PCM container will function as an 'auxiliary evaporator' to maintain cabinet temperatures within an acceptable range. Accordingly, the PCM charge should be enough to take that role and be determined from experiment measurements. More detailed explanation can be found from our previous paper [11].

\section{Model description}

The 2D model has been developed by employing a finite volume method and CFD software ANSYS Fluent 14 in order to simulate the circulated air flow through the cabinet in terms of temperature and velocity.

\subsection{Mesh}

As depicted in Fig. 3, triangle structured mesh is employed to define the geometry of the calculation domain, exempting products which are assigned as squares elements. Grid independence analysis has been considered and the number of grid points is progressively increased from one simulation to another. The refinement is stopped when the total node numbers and elements reached 67,426 and 121,367 respectively. The grid numbers for the places near products, cabinet walls and shelves, where the air flow is important, are purposely increased with specific mesh structures.

\subsection{Assumptions and boundary conditions}

The solver properties used in this model are pressure based type, absolute velocity formulation and planar $2 \mathrm{D}$ space. The following conservation equations are applied in the 2D CFD model.

Pressure-based assumes the fluid is incompressible, $\rho=$ constant , independent of space and time, so that $\partial \rho / \partial t=0$. The continuity equation will be:

$$
\frac{\partial U}{\partial x}+\frac{\partial V}{\partial y}=0
$$

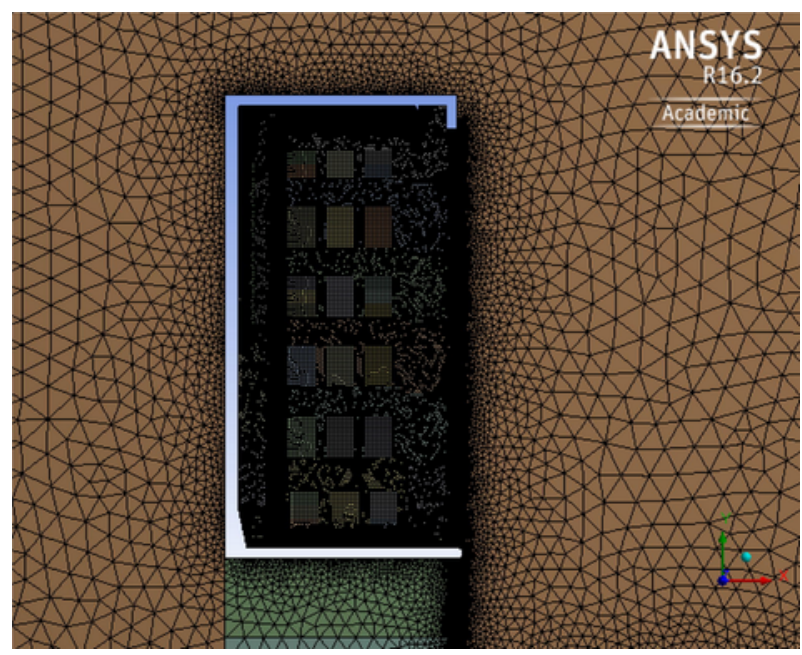

Fig. 3. Computational grids for the 2D CFD model. 
Momentum equations:

$\rho \frac{D u}{D t}=-\frac{\partial p}{\partial x}+\mu\left(\frac{\partial^{2} u}{\partial x^{2}}+\frac{\partial^{2} u}{\partial y^{2}}\right)$

$\rho \frac{D v}{D t}=-\frac{\partial p}{\partial y}+\mu\left(\frac{\partial^{2} v}{\partial x^{2}}+\frac{\partial^{2} v}{\partial y^{2}}\right)$

Energy equation:

$$
\frac{\partial T}{\partial t}+U \frac{\partial T}{\partial x}+V \frac{\partial T}{\partial y}=\frac{q}{\rho c}+\alpha\left(\frac{\partial^{2} T}{\partial x^{2}}+\frac{\partial^{2} T}{\partial y^{2}}\right)
$$

The cross section of the entire air conditional chamber (test chamber) including the cabinet is considered as a computational domain in which the right (facing the opening of the cabinet) and left (facing the back side of the cabinet) sides of the chamber are defined as pressure outlet and inlet respectively. In addition, the boundary temperature is used to identify internal emissivity and the external black body temperature is assumed to be constant. As listed in Tables 1 and 2, various thermal parameters such as the cabinet fan pressure jump are obtained from the experimental measurements and the turbulence data from assumptions. The floor and ceiling of the test chamber, and the external cabinet walls are defined as adiabatic walls. Furthermore, evaporator fan, the small holes of the perforated back panel and air curtain grill are all treated similar to the real case in the CFD model without any approximation, whereas the rest of internal edges are all categorized as walls with coupled thermal conditions.

In addition, turbulent flow assumption is made for the flow regime and the standard $\mathrm{k}-\varepsilon$ two-equation model was applied [14] as listed in Eqs. (5) and (6). The discrete ordinates method (DO) is used to simulate the coupling of radiation and convection heat transfers [15]. The effect of moisture in the air content of the test chamber is not considered, as it is thought insignificant to the simulation of the air temperature pattern [16], and the air humidity would be a common factor between the two cases with and without PCM. Furthermore,

Table 1

Experimental data.

\begin{tabular}{ll}
\hline Experimental parameters & Value \\
\hline Fan pressure jump $(\mathrm{Pa})$ & 25 \\
Ambient temperature $(\mathrm{K})$ & 298.15 \\
Food products properties & $\rho=1000 \mathrm{~kg} / \mathrm{m}^{3}, \mathrm{CP}=3500(\mathrm{~J} / \mathrm{kg} \mathrm{K}), \mathrm{K}=1 \mathrm{~W} /$ \\
& $\mathrm{m} \mathrm{k}$ \\
Instant power consumption & 1.6 \\
$(\mathrm{~kW})$ & 10 \\
Time step (s) & 24 \\
Experiment duration $(\mathrm{h})$ & \\
\hline
\end{tabular}

Table 2

Simulation assumption data

\begin{tabular}{ll}
\hline Assumption parameters & Value \\
\hline Initialization method & Standard \\
Reference frame & Relative to cell zone \\
Time step size (s) & 0.25 \\
Number of time steps & 2880 \\
Time stepping method & Fixed \\
Maximum iteration/time step & 20 \\
\hline
\end{tabular}

the weight loss of the product is not considered as the load is only packaged as chilled products. The temperature and velocity contours are assumed as uniform with reasonable approximation because of the effect of the honeycomb curtain.

$$
\begin{aligned}
& \frac{\partial(\rho k)}{\partial t}+\frac{\partial(\rho u k)}{\partial x}+\frac{\partial(\rho v k)}{\partial y} \\
& =\frac{\partial}{\partial x}\left(\Gamma_{k} \frac{\partial k}{\partial x}\right)+\frac{\partial}{\partial y}\left(\Gamma_{k} \frac{\partial k}{\partial y}\right)+S_{k}
\end{aligned}
$$

$$
\begin{aligned}
& \frac{\partial(\rho \varepsilon)}{\partial t}+\frac{\partial(\rho u \varepsilon)}{\partial x}+\frac{\partial(\rho v \varepsilon)}{\partial y} \\
& =\frac{\partial}{\partial x}\left(\Gamma_{\varepsilon} \frac{\partial \varepsilon}{\partial x}\right)+\frac{\partial}{\partial y}\left(\Gamma_{\varepsilon} \frac{\partial \varepsilon}{\partial y}\right)+S_{\varepsilon}
\end{aligned}
$$

\subsection{User defined function codes}

The user defined functions (UDFs) are necessarily included in the CFD model considering the transient operation of cabinet. The point where the cabinet controller thermostat sensor was installed during the test is monitored and computed so as to control the compressor on or off and defrost termination time. In addition, the cabinet evaporator is assumed as a constant heat sink when the compressor is on. These lead to the definitions of three types of predefined DEFINE macros.

The first one is named DEFINE_SOURCE macro to specify a heat source/sink in the evaporator region to act as the evaporator role inside the cabinet by removing the heat from the circulated air. The value of this source is assumed constant when the compressor is on and can be calculated according to the sensible capacity of the cabinet evaporator as listed in Eq. (7). The second type is EXECUTE_AT_END macro which will check the cabinet temperature at the thermostat sensor point at the end of each time step and work as a thermostatic controller. The last macro is DEFINE_INIT that is used to set initial values of flow quantities.

$$
Q_{\text {evap }}=-\dot{m}_{a} C_{p a}\left(T_{\text {airon }}-T_{\text {airoff }}\right)
$$

$$
Q_{\text {source }}=Q_{\text {evap }} / V_{\text {evap }}
$$

According to the Eq. (8) the amount of the heat source is about $-20,000 \mathrm{~W} / \mathrm{m}^{3}$. The inlet is a fan with constant pressure jump profile.

\subsection{Steady and transient state simulation}

The first stage of the simulation has been implemented in the steady state condition, which is important to gain primary validation with the experimental results and also to use it as initial conditions for the transit simulation later on. In this stage, of those three UDFs only the DEFINE SOURCE macro is needed.

After reaching the steady state result, a time dependent model is initialised to study the trend of cabinet temperature and energy consumption with time [17], taking also into account the defrost effect [18]. At this stage, the model starts from integrating all UDF codes to the main boundary conditions. All other boundaries are still the same. The calculations will continue for three days to give enough time for the transient data to stabilise. All simulation results including air cur- 
tain velocity and temperatures of products, air curtain, and return grill and evaporator air on are monitored and recorded to separate files for data analysis later on.

\subsection{PCM model}

It is important to select the optimal PCM in any particular thermal application to fulfil terms of operation and cost. PCM based water is one of the most comprehensively studied PCMs in low temperature applications considering its availability, stability and superb thermal properties [19]. Long term performance and stable thermal characteristics of PCMs are the prerequisite for longer equipment life. In addition, the latent heat should be as high as possible to decrease the size of the PCM container.

In this model, water is used as a PCM and the heat transfer to and from the PCM involves convective mode. The PCM storage is modelled as a rectangle container unit on the back panel flow duct after the evaporator and indirect contact with the circulating air through the cabinet. The phase transition temperature is constant $\left(0^{\circ} \mathrm{C}\right)$ and matches to the air cabinet temperature. The energy will then be released from or stored in the PCM during solidification and melting processes depending on the temperature.

The method used for modelling the solidification/melting process in ANSYS Fluent is the enthalpy-porosity technique [20,21]. In this approach, a quantity called the liquid fraction, which represents the fraction of the cell volume that is in liquid form, is associated with each cell in the domain. The liquid fraction is computed at each iteration, based on an enthalpy balance. The enthalpy of the material is computed as the sum of its sensible enthalpy, h, and latent heat, $\Delta \mathrm{H}$ :

$$
H=h+\Delta H
$$

where

$$
h=h_{r e f}+\int_{T_{r e f}}^{T} C_{p} d T
$$

The liquid fraction, $\beta$, is defined as

$$
\beta=\left\{\begin{array}{cc}
0 & \text { if } T<T_{s} \\
1 & \text { if } T>T_{l} \\
\frac{T-T_{s}}{T_{l}-T_{s}} & \text { if } T_{s}<T<T_{l}
\end{array}\right.
$$

The latent heat content can now be written in term of the latent heat of the material, L:

$$
\Delta H=\beta L
$$

The latent heat content can vary between zero (for a solid) and L (for a liquid).

For solidification/melting problems, the energy equation is written as:

$$
\frac{\partial}{\partial t}(\rho H)+\nabla \cdot(\rho v H)=\nabla \cdot(K \nabla T)+S
$$

The solution for temperature is essentially iterated between Eqs. (11) and (13)

\subsection{Mesh adaption}

ANSYS Fluent has the solution-adaptive mesh refinement feature which allows us to refine and/or coarsen the mesh based on geometric and numerical solution data. By using this feature properly, extra cells can be added where necessary, thus enabling the features of the flow field to be better resolved. In the meantime, computational resources are not wasted by the inclusion of necessary cells, as occurred in the grid independence approach. For this purpose, three different grids number were studied by using increasingly fine grids till the maximum product temperature difference is about $0.3{ }^{\circ} \mathrm{C}$. The grid numbers are selected as $117,143,119,811$ and 121,367 and correspondingly the product temperatures of those grid number sets are depicted in Fig. 4. Finally, the third grid system 121,367 is used for further computation.

\section{Model validation}

Designed test conditions were implemented for experimentations, of which chamber space temperature and air relative humidity were controlled to be $25{ }^{\circ} \mathrm{C}$ and $60 \%$ respectively. The simulation process is divided into two parts; the first one is steady state analysis to prepare appropriate initial conditions for the second part which is transient analysis. Of course, this stage of simulation is for the cabinet without PCM since there is no point to add it to the steady calculation. The contours of air and product temperatures and air velocity at steady state are depicted in Fig. 5. It can clearly identify the heat exchange around the air curtain, where the air curtain efficiently stands as an obvious heat transfer barrier between the internal display cabinet space and the indoor space air. It can also be observed from Fig. 5 that an air curtain is formed between discharge air grille and return air grille. The product temperatures are affected by both the cold air flow penetrating from the cabinet back panel and the warm surrounding ambient air temperature through the air curtain. Therefore, the food packages in vicinity close to the air curtain have relatively higher temperatures than those nearer to the perforated back panel such as product numbers 1-4 because of the interaction between the cold back panel flow and the air curtain. In addition, since more cold air flows from the back panel join and pass through the products of 9 and 10 before entering the return grill, the product temperatures of numbers 9 and 10 are relatively lower than those of product numbers 11 and 12 .

Similarly, the graph in Fig. 6 shows the steady state simulation and experiment results without PCM for temperatures of products

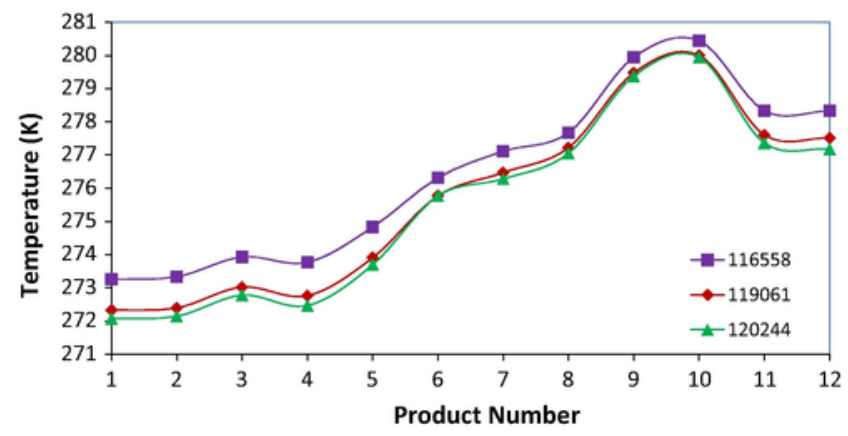

Fig. 4. Mesh adaption based on product temperatures 
(a)

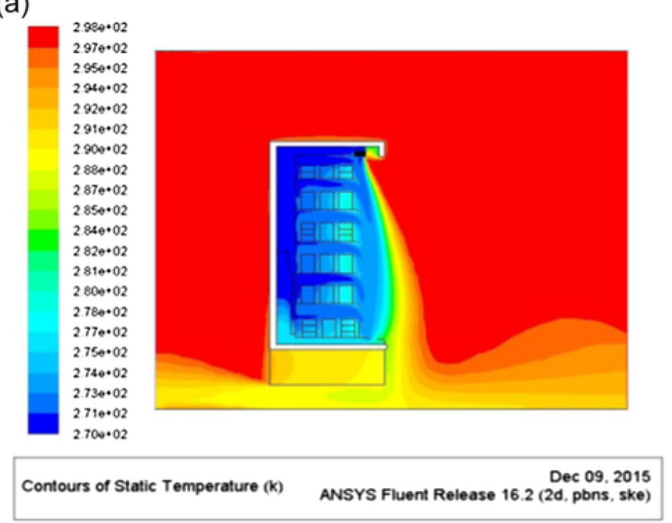

(b)

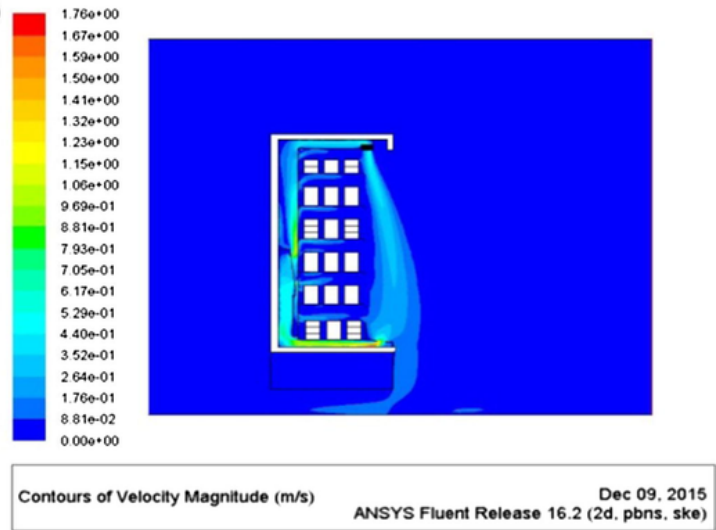

Fig. 5. (a) Air and product temperature contours and (b) air velocity contours for steady model.

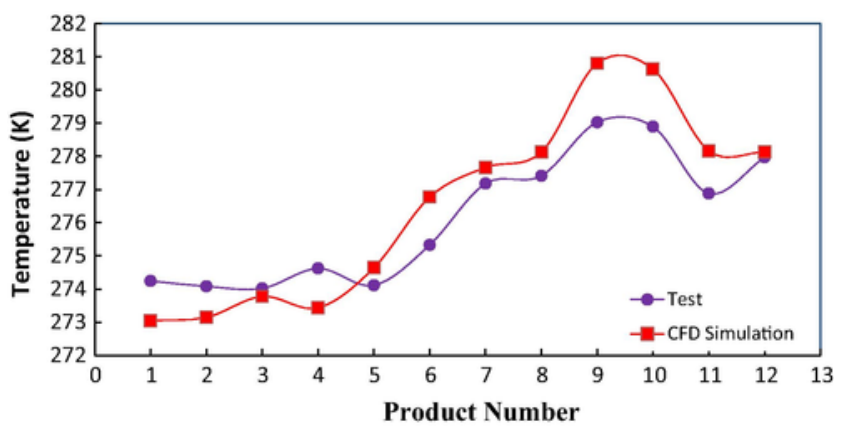

Fig. 6. Validation of products temperature for Steady mode without PCM.

numbered in Fig. 2. It should be noted that the simulation temperatures of those numbers of 1-4 products are maintained at around $274.5 \mathrm{~K}$, which are quite close to the experimental results. For the rest of products, the numerical results are slightly higher than those of the experimental measurements. However, the numerical results show good agreement with the experiments, indicating that the present computational method can efficiently simulate the heat transfer performance of the display cabinet.

As the temperature difference of every two close mounted products is quiet small, they are thus integrated into six instead of twelve product temperatures in Fig. 7 by taking the average temperature of those two close products. As shown in this Figure for the variations of six product temperatures without PCM for stable measurement and calculation, we can see the validation of our transient simulation by comparing experimental product temperatures with simulation results. By matching the colours, we can see good agreement between

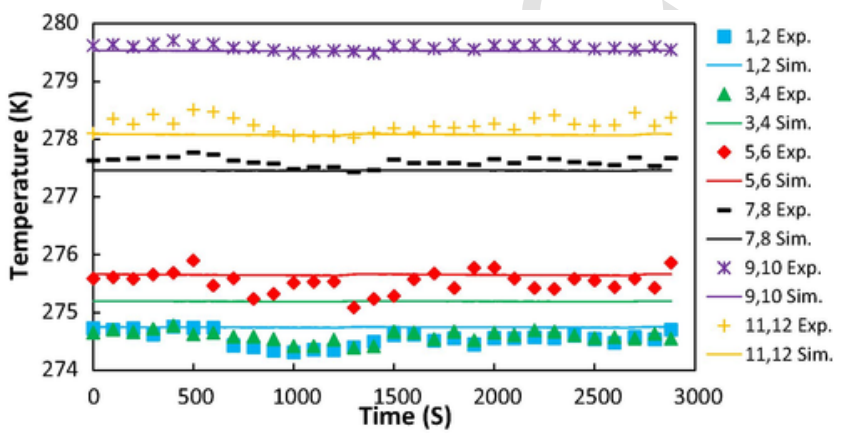

Fig. 7. Validation of products temperature for transient model without PCM. both data in which the maximum temperature difference between the simulation and experiment results is about $0.8^{\circ} \mathrm{C}$. Also, it is noticed that the temperatures of product numbers $1-4$ are much lower than others since they are closer to the highest flow rate of cold air coming through the back panel holes.

The installation of PCM would affect the air flow distribution inside the cabinet which could be predicted by the CFD models for the cabinets with and without PCM. However, the effect of PCM installation on the air flow distribution was minimised by selecting optimally the size and installation position of the PCM heat exchanger in the cabinet. Other simulation results for the cabinet with PCM including cabinet air velocity (Fig. 8), air-off temperature (Fig. 9) is also in good agreement with the measurement results. However, some inconsistencies are observed between simulation and measurements results particularly for the cabinet air-off temperature. This could be argued that not all PCM was effective during the experiment such that the

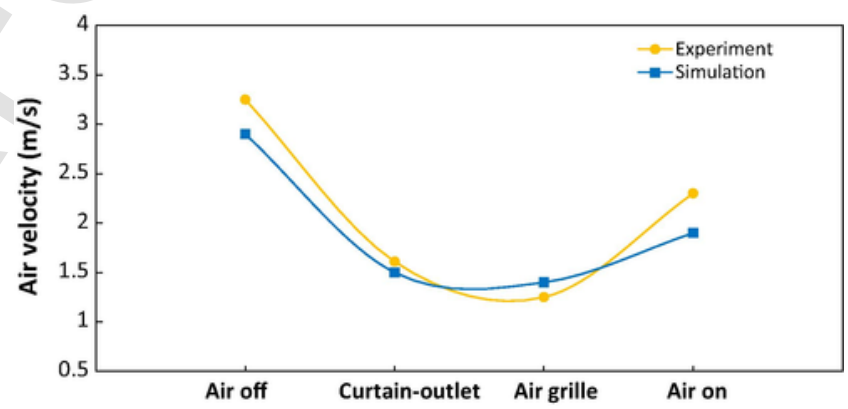

Fig. 8. Validation of air velocity for Steady model with PCM.

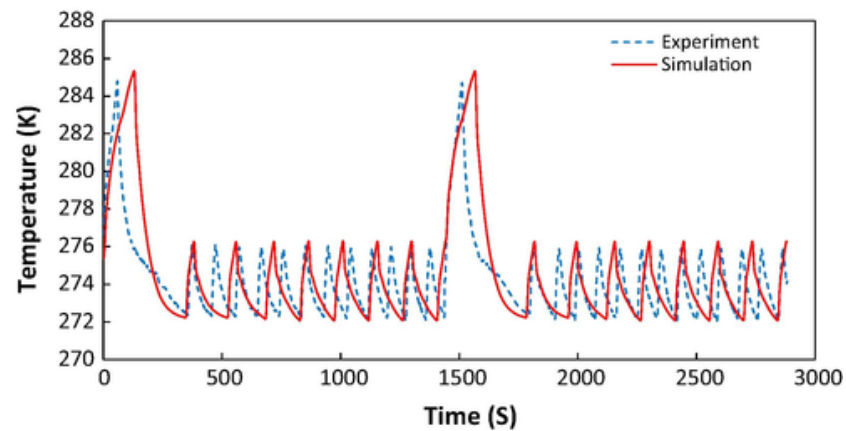

Fig. 9. Validation of evaporator air-off temperature for Transient model with PCM. 
defrost period for the test was shorter than that of simulation. On the other hand, the air velocity is an important factor for this study due to its impact of convection heat transfer on charging and discharging of PCM.

Liquid fraction contours for the melting process of big (defrost) cycle for the PCM are demonstrated in Fig. 10, in which the average liquid fraction contours are taken at $0 \%, 25 \%, 50 \%, 75 \%$ and $100 \%$ and the discharge and charge processes take place every big and short cycle. Although not all PCM is transformed into liquid in small cycles, we could still notice some good effects of the PCM integration on the cabinet air temperatures as depicted in the results. In addition, it is clearly found that liquid fraction ratio is higher at the PCM container or cabinet top due to higher air temperature. It can be readily acknowledged that the simulation and experiment results of the cabinets with and without PCM match fairly well.

\section{Result and discussion}

Due to the complexity of the developed CFD model, it would take a few days for the simulation to approach stabilization and until then the simulation results could be collected. The simulation results include mostly the performance comparisons for the cabinet with and without PCM integration.

\section{Mass Fraction}
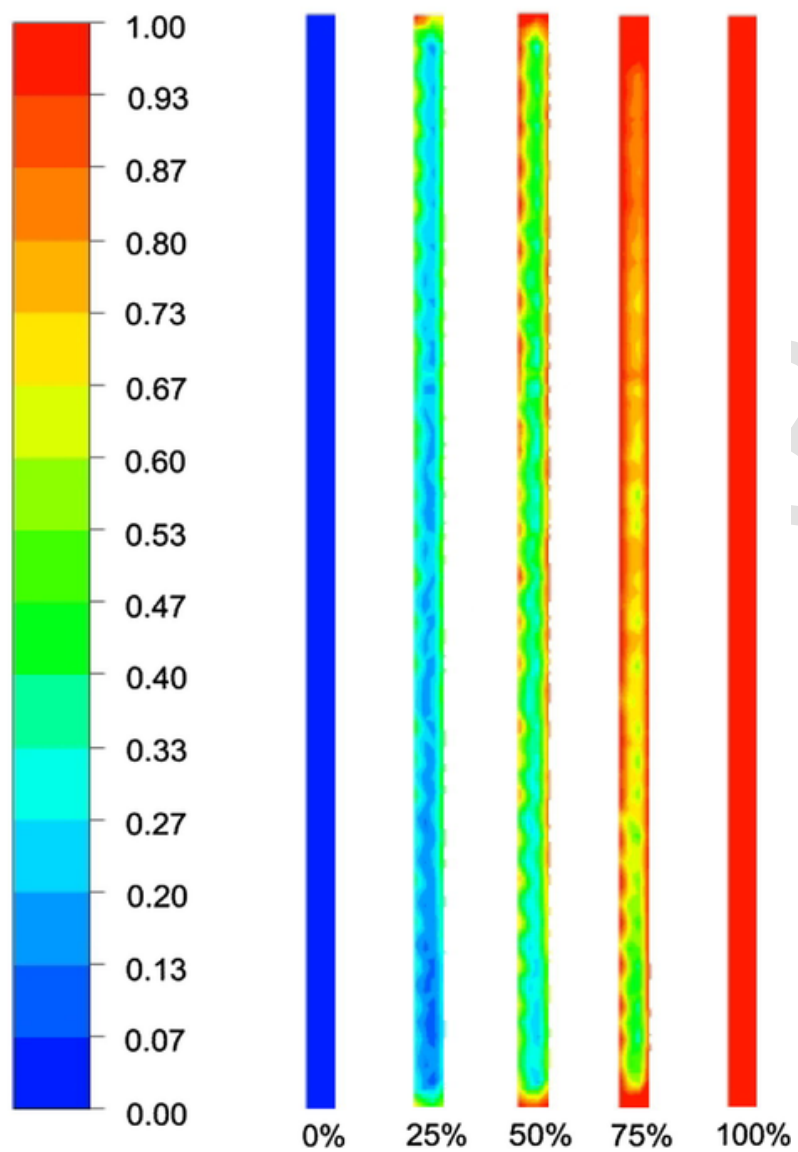

Fig. 10. Liquid fraction contours for PCM container.

\subsection{Cabinet air temperatures}

Fig. 11 distinctly shows the influence of PCM on the cabinet air temperatures at evaporator air-off, curtain outlet and air-grille. It can be observed from this figure that the maximum temperatures of cabinet air in the original cabinet are higher than those with PCM setup because the PCM absorbs some heat from the circulated air during the system off periods. Also, the minimum temperatures of original cabinet are lower than those corresponding ones with PCM due to the PCM is considered as an extra load in the on periods while the cooling capacity maintains constant. Another PCM effect demonstrates that the number of small on/off cycles decreases considerably from 11 to 8 due to the duration increase of each cycle. In addition, the defrost time period also shows increase for the modified cabinet with PCM. All these positive effects of the improved cabinet will contribute the reduction of cabinet power consumption as described below.

\subsection{Defrost and normal operation cycles}

There are two operational cycles for the cabinet compressor on and off, defrost (big) and normal (small). Every four hours, the unit is switched off for defrost until the monitored (thermostat) temperature is higher than the limitation or the defrost period is complete. Apart from the defrost period, the unit compressor enters into the normal (small) cycles and is controlled on and off based on the thermostat temperature prediction and settings. The temperature variations at the thermostat point for the cabinet with and without PCM in the period of defrost and normal are predicted and shown in Fig. 12. It is noted that the temperature variation is more restrained for the cabinet with PCM which will be helpful for the temperature uniformity of food products stored. In addition, the addition of PCM has a significant

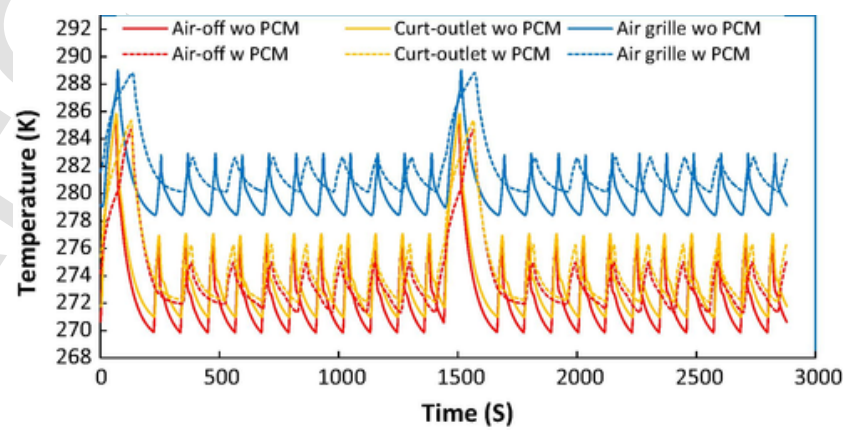

Fig. 11. Variations of cabinet air temperatures with time during period of $8 \mathrm{~h}$ with and without PCM.

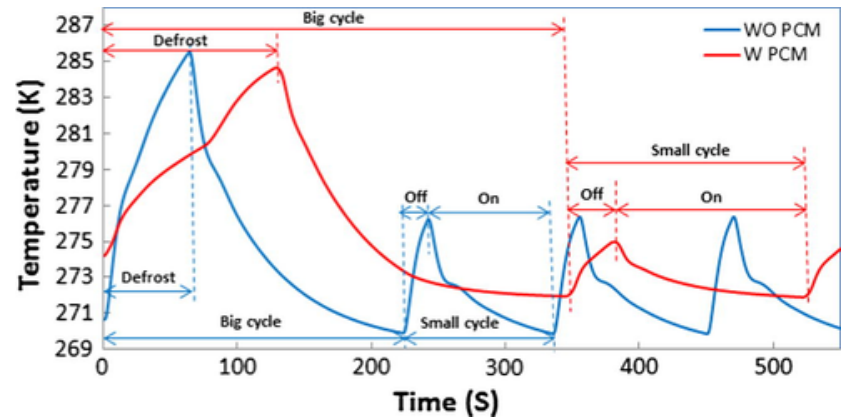

Fig. 12. Defrost, Off and On durations with and without PCM. 
impact on the total working time of the cabinet compressor in which the big and small cycle durations for the cabinet with PCM increase about $55 \%$ and $26 \%$ respectively. These are the reasons of the continuous heat transfer processes between the cabinet air flow and the integrated PCM. For any defrost or normal cycle, both on and off periods are increased for the modified cabinet. However, the increase rate for off period is more significant than that of on period due to the heat sink and source roles of PCM in these periods respectively. This leads to longer off period for the unit compressor and thus saving energy.

The energy extracted from the PCM provides the cooling needed when the compressor was stopped, which, with optimization, may achieve more energy reduction than the basic cabinet without PCM (see Table 3).

\subsection{Product temperatures}

The food product temperatures for the cabinet without and with PCM storage container were recorded during $8 \mathrm{~h}$ of stable calculation period as shown in Fig. 13a and b respectively. In each figure, there are 12 predicted product temperatures represented under different product numbers (see Fig. 2). Generally, it can be noticed from these figures, for both circumstances, the range of each product temperature remains stable with very slight variation in response to the compressor on, off and defrost. For the modified cabinet, the whole variation range of product temperatures is more moderate than that without PCM signifying more uniformity in product temperatures. However, as predicted, the outcome of adding PCM shows an increase in the whole average of product temperatures but still within standard limitation. These simulation results of product temperatures corre-

Table 3

Thermal properties of the PCM based water.

\begin{tabular}{ll}
\hline Characteristics & Value \\
\hline Density $\left(\mathrm{kg} / \mathrm{m}^{3}\right)$ & 998.2 \\
Thermal conductivity $(\mathrm{W} / \mathrm{m} \mathrm{k})$ & 0.6 \\
Specific heat $(\mathrm{kJ} /(\mathrm{kg} \mathrm{K})$ & 4.182 \\
Melting and freezing temperature $(\mathrm{K})$ & 273.15 \\
Heat of fusion $(\mathrm{kJ} / \mathrm{kg})$ & 334 \\
\hline
\end{tabular}

spond to the predicted air temperatures shown in Fig. 11 since the air flows are in immediate contact with the products.

\subsection{Compressor working time}

Starting from defrost, the compressor on (1) and off (0) states for the cabinet with and without PCM are predicted and shown in Fig. 14. When the PCM is integrated, the cabinet has fewer frequencies for both on and off states but has longer total off period. This is because that when the compressor is off, the PCM acts as an air cooler by carrying on absorb the heat from the air flow and consequently postpones the increase speed of cabinet air temperatures until the PCM is mostly melted. When the compressor is on, the PCM starts to solidify progressively and acts as an additional load such that the on period of each cycle for the cabinet with PCM is also longer. Nevertheless, the total on period is still less for the cabinet with PCM considering of its fewer on states. The reduced on times for the compressor can also lead to longer compressor operation life. It can also bring further energy savings since the compressor needs higher power at starting point from our measurement as illustrated in Fig. 15. We can find the percentage of energy saving after adding the PCM container to the cabinet during about one day running fluent time from Table 4. It is found about $6.4 \%$ energy saving plus the saving percentage resulted from reducing the number of compressor starts.

\subsection{PCM solidification rate}

The variations of PCM container average temperature (transition temperature), thermostat temperature (indicated in Fig. 2) and the PCM average liquid fraction with time are shown in Fig. 16 for $8 \mathrm{~h}$ stable calculation. For PCM to be beneficial during defrost and normal compressor off times, the PCM temperature needs to stay close to its transition temperature $(273.15 \mathrm{~K})$ for longer periods. This is achievable as it lies within the cabinet air temperature range. It can be seen that all and part of PCM latent heat are used respectively during the defrost off and normal off time periods. It is clear that the liquid fraction increases (discharging) gradually during the defrost period until its highest value of one when the whole PCM turns to liquid. Whereas only small part of PCM turns to liquid during a normal off period as there is no enough time to change whole PCM phase. After the off point, the liquid fraction starts to decrease (charging) and then
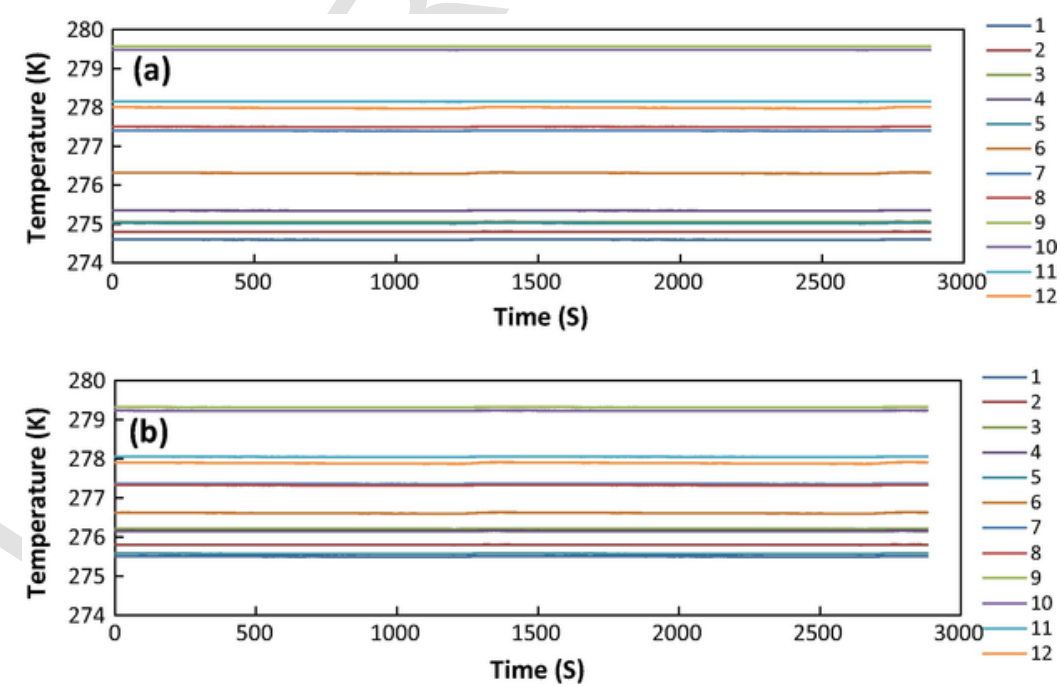

Fig. 13. Variations of products temperature with time during $8 \mathrm{~h}$ (a) without and (b) with PCM. 


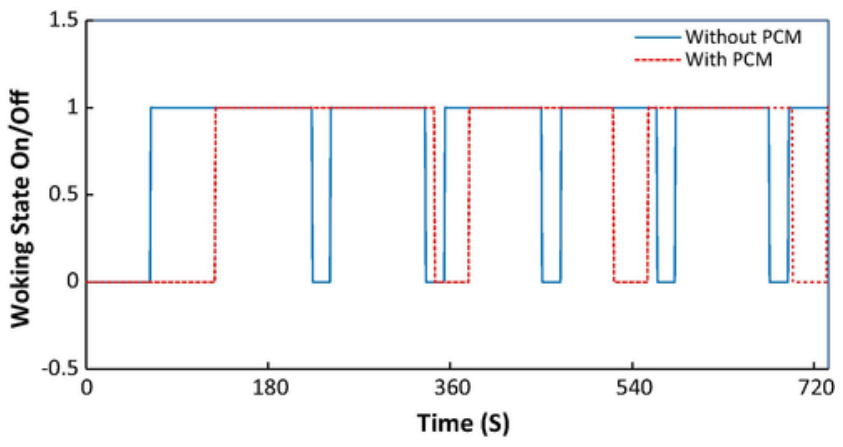

Fig. 14. Working state variations with time for cabinet with and without PCM.

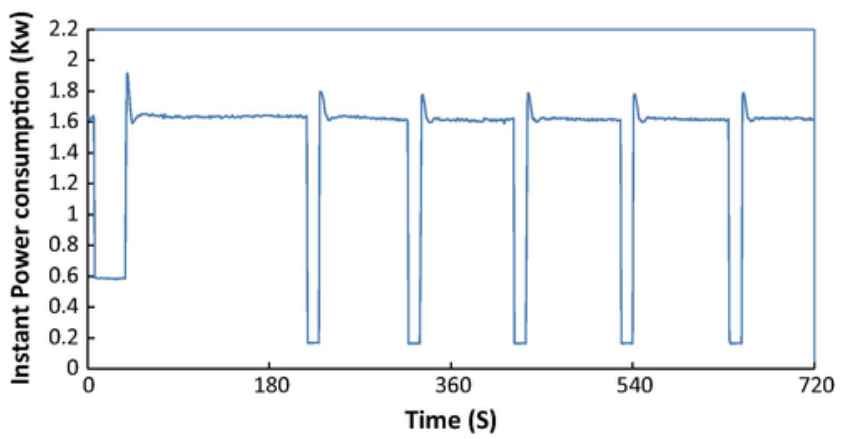

Fig. 15. Instant power consumption of experiment with time.

Table 4

Energy consumption of the cabinet in one fluent day.

\begin{tabular}{lll}
\hline Energy parameters & Without PCM & With PCM \\
\hline Average instant power $(\mathrm{kW})$ & 1.6 & 1.6 \\
Whole running time $(\mathrm{h})$ & 0.6 & 0.6 \\
Total On time $(\mathrm{h})$ & 0.4875 & 0.45 \\
Total Off time $(\mathrm{h})$ & 0.1125 & 0.15 \\
Energy consumption $(\mathrm{kWh})$ & 0.78 & 0.72 \\
No of compressor starts & 72 & 54 \\
Energy saving $(\%)$ & 6.4 & \\
\hline
\end{tabular}

increase (discharging) during the on and off working cycles, respectively.

\subsection{Variation of ambient air temperature and air velocity}

The variations of PCM liquid fraction and predicted thermostat temperature with time at different values of evaporator fan pressure jumps (or air flow rates) are illustrated in Fig. 17. It is obvious that at $20 \mathrm{~Pa}$ fan pressure jump, the PCM takes longer time to solidify after defrost as the low air velocity will decrease the transfer rate between the PCM and the circulated air flow compared to the effect of higher fan pressure jump. In this case, it will take shorter time for the thermostat sensor to reach its setting point and then switch off the compressor and thus more small cycles appeared. While the higher air velocity at $30 \mathrm{~Pa}$ pressure jump will solidify the PCM quickly such that more cooling capacity is needed for the PCM solidification and thus leading more time for the thermostat sensor to reach the setting point.

Fig. 18 indicates how the solidification process and thermostat temperature are affected by indoor space air temperature. The higher space air temperature $\left(30^{\circ} \mathrm{C}\right)$ means higher thermal load and that will make the evaporator cooling capacity not sufficient for the thermostat sensor to reach its setting point (no small cycles) and maintain product temperature at the same time. Thus, the compressor will be switched on all the time till next automatic defrost. Conversely, the lower space temperature $\left(20^{\circ} \mathrm{C}\right)$ will decrease the cabinet cooling load and allow the thermostat to reach the setting point easily but have reduced compressor off periods and more small cycles.

\section{Conclusions}

The theoretical study of a multi-deck display cabinet with a PCM heat exchanger fitted on the existing space of the main back duct demonstrates an enhancement of thermal system performance and reduction in the cabinet air temperatures when the cabinet is off. Calculations are carried out for this cabinet first without PCM integration, then with a container filled with pure water as a PCM. The simulation results show that the response of the cabinet with PCM is positive for energy savings, reducing cabinet air and product temperatures when the cabinet is off and increasing defrost and off periods. It is found that with PCM, the energy saving potential of the cabinet is significantly improved. In addition, the defrost and compressor off intervals are the most affected factors for the modified cabinet. They are increased by approximately $98 \%$ and $50 \%$ compared to those with the basic cabinet. Furthermore, a significant decrease (27\%) in the number of starts/stops of the compressor are observed for the modified cabinet. It is worth noting that energy savings vary with cabinet operational conditions such as indoor space air temperature and evapora-

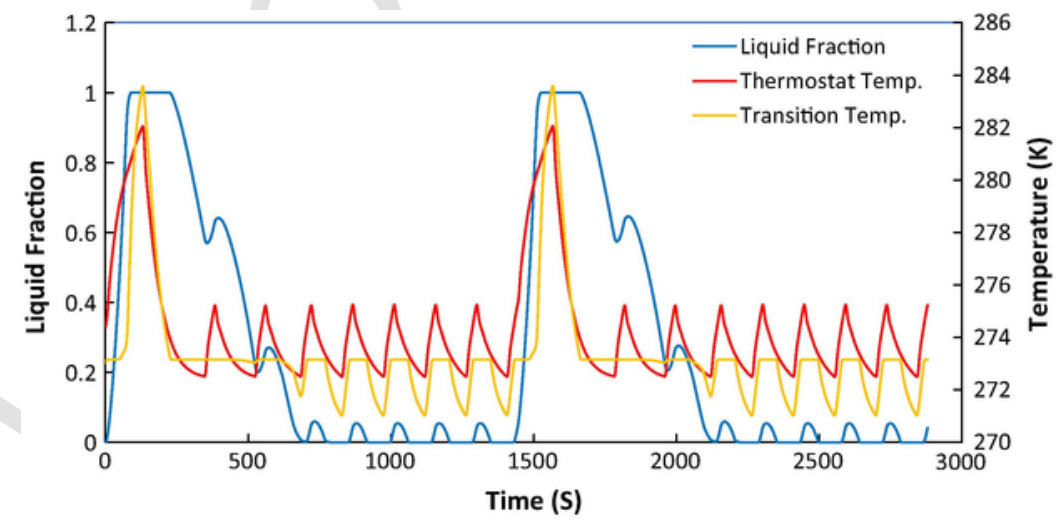

Fig. 16. Variation of melting/solidification and transition temperature with time. 


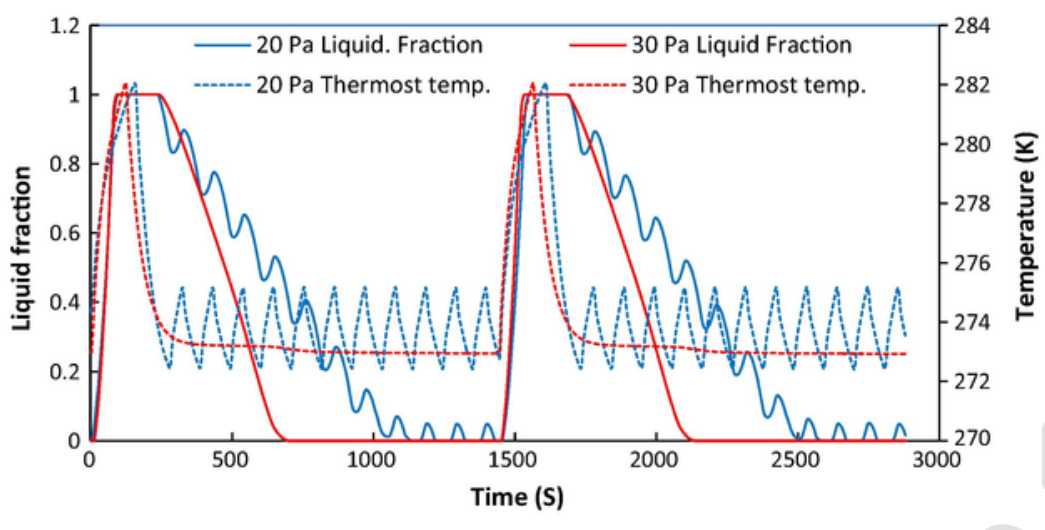

Fig. 17. Melting/solidification and thermostat temperature at different fan pressure jumps.

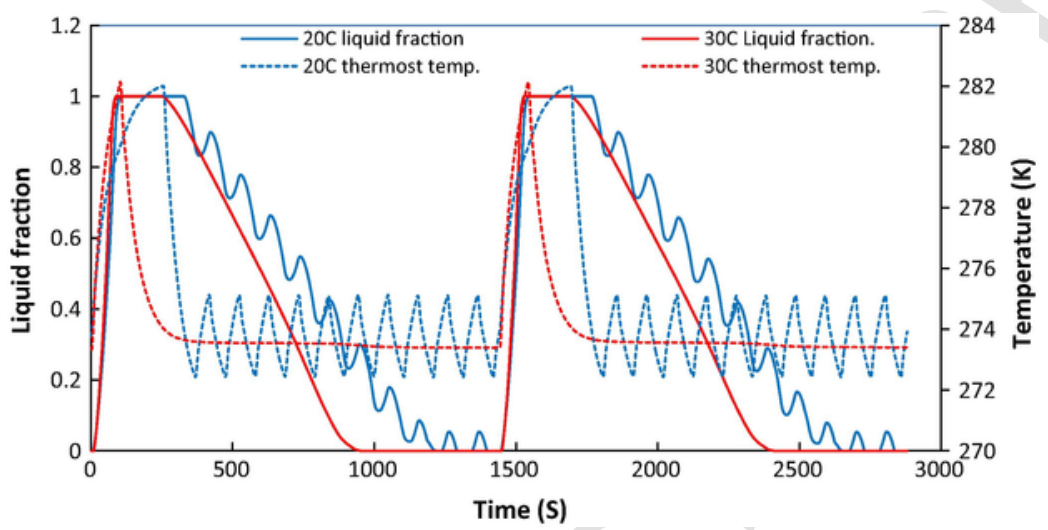

Fig. 18. Melting/solidification and thermostat temperature at different indoor space air temperatures.

tor air velocity, all of which should be considered for future models. The simulation results achieved from this work could be used to predict and optimise cabinet performance by changing various parameters such as climate class and the type, quantity and location of the PCM and PCM heat exchangers throughout the cabinet.

\section{Acknowledgements}

Work presented in this paper was carried out with financial support from the Department of Environment, Food and Rural Affairs (Defra: AFM280). The authors would like to acknowledge the support of Defra and the input from the collaborating partners.

\section{References}

[1] R. Faramarzi, Efficient display case refrigeration, ASHRAE J 41 (1999) 46-54

[2] Y.T. Ge, S.A. Tassou, Simulation of the performance of single jet air curtains for vertical refrigerated display cabinets, Appl Therm Eng 21 (2001) 201-219.

[3] Y.T. Ge, R. Cropper, Performance simulation of refrigerated display cabinets operating with refrigerants R22 and R404A, Appl Energy 85 (2008) 694-707.

[4] Y.T. Ge, S.A. Tassou, The impact of geometric structure and flow arrangement on the performance of $\mathrm{CO} 2$ evaporators in multi-deck medium temperature display cabinets, Int J Refrig 35 (2012) 142-149.

[5] A.F. Hadawey, T.J. Jaber, W.A. Ghaffar, A. Dhabi, Air curtain design optimization of refrigerated vertical display cabinet using CFD, Int J Sci Eng Technol 88 (2012) 76-88.

[6] P.D. Gaspar, L.C. Carrilho, R.A. Pitarma, CFD parametric studies for global performance improvement of open refrigerated display cabinets, Model Simul Eng 2012 (2012) 15.

[7] P.D. Gaspar, L.C. Carrilho, R.A. Pitarma, Detailed CFD modelling of open refrigerated display cabinets, Model Simul Eng 20 (2012) 17.
[8] Y.T. Ge, S.A. Tassou, A. Hadawey, Simulation of multi-deck medium temperature display cabinets with the integration of CFD and cooling coil models, Appl Energy 87 (2010) 3178-3188.

[9] F. Wang, G. Maidment, J. Missenden, R. Tozer, The novel use of phase change materials in refrigeration plant. Part 3: PCM for control and energy savings, Appl Therm Eng 27 (2007) 17-18.

[10] M. Liu, W. Saman, F. Bruno, Development of a novel refrigeration system for refrigerated trucks incorporating phase change material, Appl Energy 92 (2012) 336-342.

[11] F. Alzuwaid, Y.T. Ge, S.A. Tassou, A. Raeisi, L. Gowreesunker, The novel use of phase change materials in a refrigerated display cabinet: an experimental investigation, Appl Therm Eng 75 (2015) 770-778.

[12] W. Lu, S.A. Tassou, Characterization and experimental investigation of phase change materials for chilled food refrigerated cabinet applications, Appl Energy 112 (2013) 1376-1382.

[13] Y.L. Lu, W.H. Zhang, P. Yuan, M.D. Xue, Z.G. Qu, W.Q. Tao, Experimental study of heat transfer intensification by using a novel combined shelf in food refrigerated display cabinets (Experimental study of a novel cabinets), Appl Therm Eng 30 (2010) 85-91.

[14] B.E. Launder, D.B. Spalding, The numerical computation of turbulent flows, Comput Methods Appl Mech Eng 3 (1974) 269-289.

[15] G. Colomer, M. Costa, R. Cònsul, A. Oliva, Three-dimensional numerical simulation of convection and radiation in a differentially heated cavity using the discrete ordinates method, Int J Heat Mass Transf 47 (2004) 257-269.

[16] P. D'Agaro, G. Cortella, G. Croce, Two- and three-dimensional CFD applied to vertical display cabinets simulation, Int J Refrig 29 (2006) 178-190.

[17] R. Mastrullo, A.W. Mauro, L. Menna, A. Palma, G.P. Vanoli, Transient model of a vertical freezer with door openings and defrost effects, Appl Energy 121 (2014) 38-50.

[18] P. Bansal, D. Fothergill, R. Fernandes, Thermal analysis of the defrost cycle in a domestic freezer, Int J Refrig 33 (2010) 589-599.

[19] E. Oró, A. Gracia, A. Castell, M.M. Farid, L.F. Cabeza, Review on phase change materials (PCMs) for cold thermal energy storage applications, Appl Energy 99 (2012) 513-533.

[20] V.R. Voller, A.D. Brent, C. Prakash, The modelling of heat, mass and solute transport in solidification systems, Int J Heat Mass Transf 32 (1989) 1719-1731. 
[21] V.R. Voller, C. Prakash, Fixed grid numerical modelling methodology for convection-diffusion mushy region phase-change problems, Int J Heat Mass Transf 30 (1987) 1709-1719. 